\title{
1 Dominant carnivore loss benefits native avian and invasive mammalian scavengers
}

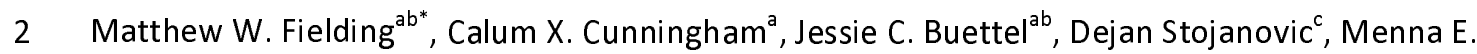

3 Jones $^{\mathrm{a}}$ and Barry W. Brook ${ }^{\mathrm{ab}}$

$4 \quad{ }^{a}$ School of Natural Sciences, University of Tasmania, Sandy Bay 7001 TAS Australia

$5{ }^{b}$ ARC Centre of Excellence for Australian Biodiversity and Heritage

$6{ }^{c}$ Fenner School of Environment and Society, Australian National University, Canberra, Australia

7

$8 *$ Corresponding Author:

9 School of Natural Sciences, University of Tasmania, Private Bag 5, Sandy Bay, TAS Australia 7001

10 Phone: (+61) 417167 618, Email: Matthew.Fielding@utas.edu.au

11 ORCID ID: https://orcid.org/0000-0003-4536-0192 


\section{Dominant carnivore loss benefits native avian and invasive mammalian scavengers}

\section{Abstract}

14 Scavenging by large carnivores is integral for ecosystem functioning by limiting the build-up of

15 carrion and facilitating widespread energy flows. However, top carnivores have declined across the

16 world, triggering trophic shifts within ecosystems. In this study, we use a natural 'removal

17 experiment' of disease-driven decline and island extirpation of native mammalian (marsupial)

18 carnivores to investigate top-down control on utilisation of experimentally placed carcasses by two

19 mesoscavengers - the invasive feral cat and native forest raven. Ravens were the main beneficiary of

20 carnivore loss, scavenging for five times longer in the absence of native mammalian carnivores. Cats

21 scavenged on almost half of all carcasses in the region without dominant native carnivores. This was

22 eight times more than in areas where other carnivores were at high densities. In the absence of

23 native mammalian carnivores, all carcasses persisted in the environment for 3 weeks. Our results

24 reveal the efficiency of carrion consumption by mammalian scavengers. These services are not

25 readily replaced by less-efficient facultative scavengers. This demonstrates the significance of global

26 carnivore conservation and supports novel management approaches, such as rewilding in areas

27 where the natural suite of carnivores is missing.

28 Keywords: scavenger, trophic cascade, carcass use, survival analysis, mesoscavenger release,

29 carnivore extinction 
30

31

32

33

34

35

36

37

\section{Introduction}

Scavenging is ubiquitous among mammalian and avian carnivores, with most species scavenging to some degree [1-4]. Larger carnivorous mammals are highly efficient scavengers, consuming carcasses faster than most other taxa [5]. However, many larger mammalian carnivores, as well as obligate scavengers like vultures, are experiencing widespread declines due to habitat loss, disturbance, and persecution by humans [6, 7]. Fluctuations in the abundance of these species can have trophic consequences that cascade throughout the food web and impact nutrient cycling and disease transmission [8-10]. With populations of some larger mammalian carnivores now beginning to recover, this raises questions around how scavenging dynamics have shifted within modified ecosystems [11].

Larger mammalian carnivores can either provision ecosystems with a more stable supply of carrion (e.g. wolves in Yellowstone National Park [12]), or limit carrion access (e.g. bears kleptoparasiting cougar kills [13] and Tasmanian devils reducing carrion availability [14]). Carrion is a high-quality resource with low handling costs, and thus is attractive to mesoscavengers [1]. However, scavenging on carrion is also risky due to the increased likelihood of encountering dominant scavengers [15-17]. These competitive and facilitative processes can potentially make carrion "fatally attractive" for mesoscavengers [18]. For example, mesoscavengers were attracted to wolf kills yet were negatively associated with wolf density at the landscape scale [19]. Although carcasses are attractive to mesoscavengers, predator avoidance plays an important role in shaping carnivore communities [18, 20].

Across the southern-temperate continental island of Tasmania (Australia) and its large offshore islands (Fig. 1; total area: $68,401 \mathrm{~km}^{2}$ ), a large-scale natural experiment is occurring due to the severe population decline of the largest extant terrestrial carnivore, the marsupial Tasmanian devil Sarcophilus harrisii [20]. Devils are Tasmania's dominant scavenger, being both the largest extant terrestrial mammalian carnivore and a specialist, although facultative, scavenger adapted for 
55 processing the toughest parts of carcasses [21]. Following the extinction of the thylacine Thylacinus

56 cynocephalus in the $20^{\text {th }}$ century, this mesocarnivore has become the apex terrestrial carnivore [20,

$5722,23]$. Devils have experienced severe population declines due to a transmissible cancer, devil

58 facial tumour disease (DFTD) [24]. The disease has progressively spread across Tasmania over 25 years, causing average population declines of $83 \%$ across $\sim 90 \%$ of Tasmania $[25,26]$. The progressive spread of DFTD has established a natural experiment by creating regions of Tasmania with different disease histories and consequently, widely variable densities of top carnivores. Unlike most the effects of a carnivore's abundance with little anthropogenic confounding. In areas where devils have declined, carrion persists three-fold longer, allowing increased carrion consumption by native (spotted-tailed quolls Dasyurus maculatus) and invasive (feral cats Felis catus) mammalian and avian (forest ravens Corvus tasmanicus) mesoscavengers [14]. However, this prompts the question: what would happen to carrion if all native mammalian carnivores were completely lost? Can invasive and avian mesoscavengers then fully replace the ecosystem services of larger mammalian scavengers?

The Bass Strait Islands, between Tasmania and the Australian mainland, are ecologically similar to mainland Tasmania due to intermittent land connectedness during glacial maxima [27]. However, following major land-use change and human persecution, several species were driven to extinction on the islands, including mammalian carnivores like spotted-tailed quolls $[28,29]$. While there is no evidence of the Tasmanian devil on the islands following European occupation, on Flinders Island, fossil evidence suggest that devils may have persisted until at least 8000 years ago [29, 30]. This mensurative experiment on the Bass Strait Islands thereby provides a unique opportunity to compare scavenging between: 1) a full community (Tasmanian mainland) comprising a native mammalian apex scavenger, native mammalian mesoscavenger, invasive mammalian mesoscavenger and native avian mesoscavenger; 2 ) a community in which only the native apex native mammalian scavengers (Bass Strait Islands). 
81 In this study, we used experimentally deployed carcasses $(n=136)$ and camera traps to monitor

82 carrion use by mammalian and avian scavengers across mainland Tasmania and the two largest Bass

83 Strait Islands. Using this design, we investigated how the abundance and occurrence of native top

84 scavengers (devils) and native mesoscavengers (quolls) impacts: (i) carrion use and discovery by

85 invasive and extant native mesoscavengers, and (ii) carcass persistence within an environment. We

86 hypothesised that avian generalist mesoscavengers (ravens) and invasive mesoscavengers (feral cats)

87 will not match the scavenging efficiency of devils and predicted that carcasses should persist for

88 longer in their absence. We also expected that top native mammalian scavengers (devils) would limit

89 carrion access and total feeding time for other smaller scavengers. Furthermore, we hypothesised

90 that devils would have a stronger impact on the scavenging community than smaller native

91 mesoscavengers (quolls).

Methods

94 Study area

We measured carrion use by mammalian and avian scavengers across Tasmania and the two largest

Bass Strait Islands in south-eastern Australia (Fig. 1). In Tasmania, the progressive westward spread 
106

107

108

109

110

community: 40). Camera sites were placed in a roughly even mixture of wet eucalypt/rainforest

habitat and dry eucalypt/coastal scrub habitat and we selected areas where human influence was minimal.

\section{Experimental design}

Carcasses were deployed during August - September 2016 for the Tasmanian mainland, and August September 2020 on the Bass Strait islands. We worked in late winter, when consumption by invertebrate scavengers and microbial decomposers is at its lowest. We used Bennett's wallaby (Macropus rufogriseus) and Tasmanian pademelon (Thylogale billardierii) carcasses. These are both regularly culled under crop-protection permits and are a common source of carrion in the study region. The carcass species used at a given site depended on local availability. To ensure independence, carcasses were deployed at least $1 \mathrm{~km}$ apart. At each carcass, we installed one camera trap (Cuddeback X-Change 1279 or Reconyx PC-800) to monitor scavengers. Cameras were deployed for a minimum of 21 days, after which we expected the carcasses to be mostly consumed.

\section{Analysis}

\section{i) Carcass discovery \& persistence}

We used statistical survival analysis based on a mixed-effects Cox proportional hazards model from the R package 'coxme' [31] to study carcass discovery and persistence. We ran separate analyses to investigate the time it took for the carcasses to be discovered by (i) any vertebrate scavenger, (ii) ravens, and (iii) feral cats. Discovery was defined as the first time an animal found and fed on the carcass. Carcasses were defined as fully consumed when there was a clear final consumption event, and the physical carcass was absent from subsequent images. If the final event was not clear, we 
used the $95^{\text {th }}$ percentile foraging event, when foraging activity petered out over many days, given the carcasses appeared to be more than $95 \%$ consumed.

We used survival analysis because the discovery and persistence data were censored [32]. Discovery data were right-censored because not every carcass was discovered by ravens and feral cats before the carcass was completely consumed. The persistence data were also right-censored because memory cards occasionally became full before complete consumption $(n=9)$, several carcasses were prematurely removed from the view of the camera $(n=18)$, one camera returned no images throughout the study, and the batteries in one camera failed before the carcass was fully consumed.

We selected the preferred survival models using the package 'MuMIn' [33] with combinations of four predictor variables: devil activity (number of devil detections per 100 camera nights), quoll activity (number quoll detections per 100 camera nights) and habitat (wet vs dry forest), with initial carcass weight $(\mathrm{kg})$ included as a covariate to account for variation in carcass size (see Table S1 in the Supplementary Information for model combinations). To account for variation across the study sites, we used site location as a random effect. All the predictors had a Pearson's cross-correlation coefficient $r<0.7$. Model selection was based on Akaike's information criterion corrected for a small sample size $\left(A I C_{c}\right)$. The most parsimonious models were selected using $\Delta A I C_{c}<2$ (difference between the $\mathrm{AIC}_{\mathrm{c}}$ of a given model and the best model) (Grueber et al. 2011). For each supported covariate (where 95\% confidence limit did not overlap with zero), we calculated the model-averaged exponentiated coefficients, known as hazard ratios (HR), which provide effect sizes for each variable. Survival curves were visualised by separating carcass data into the three regions (Fig. 1) and presenting the Kaplan-Meier estimates of the survival function using the packages 'survival' [34] and 'survminer' [35].

\section{ii) Carcass use}


153 To analyse the predictors of carcass use by forests ravens and feral cats, we tested a range of $a$ priori

154 models based on ecological knowledge (Table S2, supplementary information). We again used AIC

155 for model selection and multi-model inference. We assessed the fit of the top models by calculating

156 the AUC (area under the receiver operator curve; suitable for classification models). We tested the

157 effects of five predictor variables: habitat, devil, and quoll activity (defined above), plus total

scavenging time by devils and quolls (separately, summated minutes). To account for variation in

carcass size, we included initial carcass weight as a covariate. We also used site location as a random

effect to account for variation across the study sites. We calculated the standardised regression

coefficient (Std. coef) based on z-values for each predictor after model averaging. For any variables

that were supported (95\% confidence limit did not overlap with zero), we calculated the effect size

(ES) by comparing the model-averaged predicted probability when that categorical variable was

applied, against the probability of the intercept when the effect was absent. Sixteen cameras were

removed from the analysis in total: twelve due to premature removal of the carcass from the field of

view and four due to mechanical unreliability or early failure.

To analyse carcass use by forest ravens, we used hurdle models, because the scavenging data were

zero-inflated and followed a gamma distribution. We first modelled whether ravens fed at a carcass

(GLMs with binomial link function) and then modelled the total scavenging time by ravens for the

carcasses at which they fed (GLMs with a Gamma distribution and a log link function). Total

scavenging time for each camera was calculated by summing the number of minutes any raven

spent scavenging on the carcass. GLMs with a binomial link function were used to assess carcass use

by feral cats, but we were unable to model the predictors of total scavenging time by feral cats due 
178

179

180

181

182

183

\section{i) Carcass discovery \& persistence}

The absence of native mammalian carnivores had a significant effect on extending the persistence time of carcasses. Carcasses within the simple community region lasted 1.8 times longer than reduced community regions and 4.6 times longer than full community region (Fig. 2). 'Devil activity' had a negative effect on carcass persistence (Hazard Ratio, HR $=1.09$ ) while 'carcass weight' had a positive effect, with larger carcasses persisting for longer ( $H R=0.96)$.

There was no difference in the discovery rates between the various scavenger communities when all species were aggregated (Fig. 3a), although carcasses in wet forests took longer to be discovered (HR $=0.54)$. Ravens discovered carcasses in significantly less time at both reduced and simple scavenger community (Fig. 3b) with 'devil activity' ( $H R=0.92)$ and wet forest 'habitat' ( $H R=0.47)$ suppressing carcass discovery by ravens. Cats showed a similar but weaker response to those observed in ravens (Fig. 3c), however, there were no supported variables.

\section{ii) Carcass use}

Forest ravens were the main beneficiary of the absence of native mammalian carnivores (Table 1; Fig. 4a). As a proportion of total foraging time for all species, we found that ravens fed almost twice as long in the simple scavenger community ( $88.2 \%$ of total foraging time by all species) compared to ravens in the reduced scavenger community (47.9\%) and five times as long as in the full scavenger community (17.3\%; Fig. 4d). Both devil scavenging time (Std. coef =0.53; ES: -0.99; Fig. 4b) and devil activity (Std. coef $=0.47$; ES: $-0.98 ;$ Fig. $4 \mathrm{c}$ ) had a strong negative effect on the likelihood of a raven feeding at a carcass. However, only devil scavenging time impacted total duration of raven scavenging (Std. coef $=0.81$ ), having an overall negative effect (ES: -0.99 ; Fig. $4 \mathrm{e}$ ).

Feral cats scavenged on a higher proportion of carcasses in the absence of native mammalian carnivores. Cats in the simple scavenger community fed on $44 \%$ of carcasses, which was 2.4 times 
202

203

204

205

more than in the reduced community region (19\%), and eight-fold more than in the full community region (6\%; Fig. 5a). The probability of cats scavenging was best predicted by devil activity (Std. coef $=0.65)$ and the relationship was negative (ES: $-0.91 ;$ Fig. $5 b$ ) .

\section{Discussion}

We used a naturally occurring experiment, of reduction or extirpation of native mammalian scavengers, to examine the effects on scavenging by avian and invasive-mammalian scavengers. The apex mammalian scavenger, the Tasmanian devil, had an overwhelmingly dominant effect on scavenger dynamics, with carcasses persisting 4.6 times longer in areas with a simple scavenger community structure. Smaller scavengers, most notably forest ravens, were the main beneficiary of native mammalian carnivore loss. Further, invasive cats scavenged almost $50 \%$ of all carcasses in areas with simplified carnivore communities, highlighting that-contrary to general wisdom [36, 37] - scavenging can contribute an important source of food for cats. This also suggests potential avenues for reducing the cat's devastating effects on native wildlife. Overall, this research highlights the crucial role of scavenging by larger mammals and shows that their effects are not easily replaced once lost. Rewilding of larger carnivores could restore their function within an ecosystem and provide top-down control on mesoscavenger populations (Fielding et al. 2020).

We found that smaller mesoscavengers were unable to replicate the scavenging efficiency of the larger, specialist scavenger, the Tasmanian devil [21]. In the absence of native mammalian carnivores, carcasses persisted for almost five times longer than in areas with higher mammalian carnivore diversity (Fig. 2). While a higher proportion of carcasses in the simple community region were of the larger Bennett's wallaby, the several Tasmanian pademelon carcasses we used also persisted until the end of the study. Previous research has found that mesoscavengers, including corvids, were unable to functionally replace raptors in urban areas, with $70 \%$ of fish carcasses remaining [38]. Additionally, the experimental exclusion of carcasses from vultures resulted in 10 
227 times as many carcasses not fully consumed by the remaining scavengers [39]. While all carcasses

228 within the simple community region in our study persisted until the study's end, only $5 \%$ of

229 carcasses were not discovered and scavenged upon by the remaining mesoscavengers (Fig. 3a).

230 Clearly, the absence of native mammalian carnivores had little impact on the remaining scavengers

231 locating and feeding upon the carcasses, thereby indicating little facilitation of carrion resources by

232 top scavengers through advertising or increased accessibility.

We found evidence that top carnivores limit carrion access for smaller scavengers. Ravens were the main beneficiary of native mammalian carnivore loss, with ravens in the simple community region finding $88 \%$ of the carcasses (Fig. 3b) and foraging for seven times longer than in the full scavenger community regions (Fig. 4d). Devils suppressed raven carcass utilisation (Fig. 4e), probably because nocturnal devils consumed the resources before diurnal ravens discovered them. This finding supports previous findings that under low levels of competition raven populations on the Bass Strait islands prioritise scavenging on roadkill across the entire year even when other resources (e.g.,

240 invertebrates, fruit, seeds) are available [40].

241 Until recently, cats were believed to rarely scavenge [36, 37]. However, there is now a growing body 242 of evidence that they actively scavenge, especially when they perceive little risk [41]. Our data show 243 that in the simple scavenger community, feral cats scavenged at eight times the rate of cats living in 244 a full scavenger community (Fig. 5a). Furthermore, the presence of devils in the landscape suppressed cat scavenging behaviour, potentially through interference competition (cats also being mostly nocturnal foragers). Past research has demonstrated that the presence of devils within an environment can trigger avoidance strategies in cats to evade interspecific conflict [14, 42, 43]. Reduced interference competition caused by top-carnivore loss can have cascading effects throughout an ecosystem, potentially leading to population increases of, and expanded functional roles for, smaller carnivores [44]. However, fear effects imposed by larger carnivores on 
252

253

dynamics between carnivores [18]. Combining several lines of investigation (e.g., GPS data on multiple predators combined with cameras on carcasses) would help quantify the risk-reward tradeoff of carcasses, and could help reveal under what circumstances carcasses are "fatally attractive" to mesopredators [19].

Following the disease-driven decline of devils across Tasmania, quolls also increased their use of carrion in areas of low devil density [14]. Indeed, in areas of greater devil decline, such as northEastern Tasmania, quoll scats contained many large-mammal remains, suggesting that the loss of top scavengers improved scavenging opportunities for quolls [45]. Despite quolls being mesoscavengers, they have, like devils, also been documented chasing cats from carcasses, providing evidence of interference competition [14]. However, we only found a weak effect of quoll abundance on carcass use by ravens and cats. As quolls are non-specialised and smaller scavengers, they are much less efficient than devils and it is therefore difficult for them to monopolise a carcass in the same way [46]. Additionally, the effects of devils-as a dominant and specialised scavengeron other opportunistic scavengers might simply be too strong, acting to mask any potential impacts the quoll may have on cats and ravens [21].

As highly efficient scavengers, the loss of apex scavengers can lead to increased food availability for mesoscavengers which could result in increases in abundance [1]. For example, the absence of vultures (Gyps spp.) in south-eastern Spain led to a higher abundance of red foxes (Vulpes vulpes) due to greater availability of carrion [47]. Similarly, feral dogs (Canis lupus) and rodents have increased in abundance in areas of India due to a rise in carrion availability following widespread vulture declines [48]. In the Bass Strait region, anecdotal evidence suggests that forest-raven and feral-cat populations are growing on King Island [28, 49]. Enhanced opportunities to feed to on roadkill [40] and other carrion, as demonstrated in this study, may provide explanations for this apparent increase in abundance. Further research is needed to confirm whether these species are truly increasing in abundance. Elevated numbers of forest ravens could have destructive effects for 
the local birds on the islands through heightened levels of depredation, and impact local farmers

through increased attacks on livestock, as shown in other corvid studies [41,50], as well as on King

Island specifically [51]. While past research in Tasmania found no impact of forest raven abundance

on the abundance of other bird species [52], these impacts may differ on the Bass Strait islands if the

raven population size is greater. Meanwhile, the impacts of the invasive feral cat on small mammals

or birds are well-documented, with many species now threatened with extinction or already lost due

to heightened predation risk $[53,54]$. Despite these apparent increases in abundance, feral cats and

forests ravens are less efficient scavengers than devils [46], meaning carcasses may persist in an

environment for longer. This could have adverse effects on both animal and human health due to

the increased spread of carrion-borne diseases $[1,17,55]$.

Large carnivore populations have fluctuated due to human persecution and habitat loss, causing

trophic cascades throughout food webs across the globe [6]. In our study, we found that top

ravens and cats. However, it remains unclear how this may impact mesoscavenger population

abundance and whether there are cascading effects on small prey species. In the absence of top

mammalian scavengers, we found that carcasses persisted beyond the study length ( 3 weeks).

293 Further research is required to see how this may impact the transmission of carrion-borne diseases

294 and scavenging by invertebrates. In this mensurative experiment, we demonstrate that the absence

295 of top mammalian scavengers results in the loss of essential ecosystem functions, providing support

296 for novel management approaches, such as trophic rewilding [56-58]. Overall, our findings further

297 highlight and clarify the integral role native mammalian scavengers perform within an ecosystem,

demonstrating the ecological significance of global mammalian carnivore conservation.

301 The authors would like to acknowledge the palawa peoples of lutruwita, the traditional custodians of 
302

303

304

305

306

307 the lands on which this work was completed. We extend our gratitude to the many fieldwork volunteers. We would also like to thank the Flinders Island Aboriginal Association Inc. (FIAAI) and various landowners across Tasmania who allowed us to complete fieldwork on their properties. This work was funded by the Holsworth Wildlife Research Endowment and Australian Research Council (ARC) grants FL160100101, CE170100015 to B.W.B. and DP110103069 to M.E.J.

\section{References}

[1] O'Bryan, CJ, Holden, MH \& Watson, JEM. 2019 The mesoscavenger release hypothesis and implications for ecosystem and human well - being. Ecol. Lett. 22, 1340-1348.

(doi:10.1111/ele.13288).

[2] Barton, PS, Cunningham, SA, Lindenmayer, DB \& Manning, AD. 2013 The role of carrion in maintaining biodiversity and ecological processes in terrestrial ecosystems. Oecol 171, 761-772. (doi:10.1007/s00442-012-2460-3).

[3] Devault, TL, Rhodes Jr, OE \& Shivik, JA. 2003 Scavenging by vertebrates: behavioral, ecological, and evolutionary perspectives on an important energy transfer pathway in terrestrial ecosystems. Oikos 102, 225-234. (doi:10.1034/j.1600-0706.2003.12378.x).

[4] Walker, MA, Uribasterra, M, Asher, V, Getz, WM, Ryan, SJ, Ponciano, JM \& Blackburn, JK. 2021 Factors influencing scavenger guilds and scavenging efficiency in Southwestern Montana. Sci. Rep. 11. (doi:10.1038/s41598-021-83426-3).

[5] Sebastián-González, E, Moleón, M, Gibert, JP, Botella, F, Mateo-Tomás, P, Olea, PP, Guimarães, PR \& Sánchez-Zapata, JA. 2016 Nested species-rich networks of scavenging vertebrates support high levels of interspecific competition. Ecology 97, 95-105. (doi:10.1890/15-0212.1).

[6] Ripple, WJ, Estes, JA, Beschta, RL, Wilmers, CC, Ritchie, EG, Hebblewhite, M, Berger, J, Elmhagen, B, Letnic, M, Nelson, MP, et al. 2014 Status and ecological effects of the world's largest carnivores. Science 343, 1241484. (doi:10.1126/science.1241484). 
327 [7] Buechley, ER \& Şekercioğlu, ÇH. 2016 The avian scavenger crisis: looming extinctions, trophic

328 cascades, and loss of critical ecosystem functions. Biol. Conserv. 198, 220-228.

329 (doi:10.1016/j.biocon.2016.04.001).

330 [8] Wilson, EE \& Wolkovich, EM. 2011 Scavenging: how carnivores and carrion structure

331 communities. Trends Ecol. Evol. 26, 129-135. (doi:10.1016/j.tree.2010.12.011).

332 [9] Allen, ML, Elbroch, LM, Wilmers, CC \& Wittmer, HU. 2014 Trophic facilitation or limitation?

333 Comparative effects of pumas and black bears on the scavenger community. PLOS ONE 9, e102257.

334 (doi:10.1371/journal.pone.0102257).

Monitoring the dead as an ecosystem indicator. Ecol. Evol. (doi:10.1002/ece3.7542).

[11] Chapron, G, Kaczensky, P, Linnell, JDC, Von Arx, M, Huber, D, Andrén, H, López-Bao, JV, Adamec, dominated landscapes. Science 346, 1517-1519. (doi:10.1126/science.1257553). introduced top predators: grey wolf subsidies to scavengers in Yellowstone National Park. J. Anim. Ecol. 72, 909-916. (doi:10.1046/j.1365-2656.2003.00766.x).

[13] Elbroch, LM, Lendrum, PE, Allen, ML \& Wittmer, HU. 2015 Nowhere to hide: pumas, black bears, and competition refuges. Behav. Ecol. 26, 247-254. (doi:10.1093/beheco/aru189). carnivore decline has cascading effects on scavengers and carrion persistence. Proc. R. Soc. B 285, 110. (doi:10.1098/rspb.2018.1582).

[15] Arjo, WM \& Pletscher, DH. 1999 Behavioral responses of coyotes to wolf recolonization in northwestern Montana. Can. J. Zool. 77, 1919-1927. (doi:10.1139/z99-177).

[16] Atwood, TC \& Gese, EM. 2008 Coyotes and recolonizing wolves: social rank mediates riskconditional behaviour at ungulate carcasses. Anim. Behav. 75, 753-762. (doi:10.1016/j.anbehav.2007.08.024).

353 [17] Moleón, M \& Sánchez-Zapata, JA. 2021 The role of carrion in the landscapes of fear and disgust: 354 a review and prospects. Diversity 13, 28. (doi:10.3390/d13010028). 
355 [18] Prugh, LR \& Sivy, KJ. 2020 Enemies with benefits: integrating positive and negative interactions among terrestrial carnivores. Ecol. Lett. 23, 902-918. (doi:10.1111/ele.13489).

[19] Sivy, KJ, Pozzanghera, CB, Grace, JB \& Prugh, LR. 2017 Fatal attraction? Intraguild facilitation and suppression among predators. Am. Nat. 190, 663-679. (doi:10.1086/693996).

[20] Cunningham, CX, Johnson, CN \& Jones, ME. 2020 A native apex predator limits an invasive mesopredator and protects native prey: Tasmanian devils protecting bandicoots from cats. Ecol. Lett. 23, 711-721. (doi:10.1111/ele.13473).

[21] Jones, ME. 2003 Convergence in ecomorphology and guild structure among marsupial and placental carnivores. In Predators with Pouches: The Biology of Carnivorous Marsupials (eds. M.E. Jones, C.R. Dickman \& M. Archer), pp. 281-292. Melbourne, Australia, CSIRO Publishing. induced decline of an apex predator, the Tasmanian devil. Conserv. Biol. 28, 63-75. (doi:10.1111/cobi.12152).

[24] Hawkins, CE, Baars, C, Hesterman, H, Hocking, GJ, Jones, ME, Lazenby, B, Mann, D, Mooney, N, Pemberton, D, Pyecroft, S, et al. 2006 Emerging disease and population decline of an island endemic, the Tasmanian devil Sarcophilus harrisii. Biol. Conserv. 131, 307-324.

374 (doi:10.1016/j.biocon.2006.04.010). (doi:10.1111/ele.13703). 
383 [27] Bowdler, S. 2015 The Bass Strait Islands revisited. Quat. Int. 385, 206-218.

384 (doi:10.1016/j.quaint.2014.07.047).

385 [28] Threatened Species Section. 2012 King Island biodiversity management plan. (Hobart,

386 Department of Primary Industries, Parks, Water and Environment.

387 [29] Peacock, DE, Fancourt, BA, McDowell, MC \& Abbott, I. 2018 Survival histories of marsupial

388 carnivores on Australian continental shelf islands highlight climate change and Europeans as likely

389 extirpation factors: implications for island predator restoration. Biodivers. Conserv. 27, 2477-2494.

390 (doi:10.1007/s10531-018-1546-6).

391 [30] Hope, JH. 1973 Mammals of the Bass Strait Islands. Proc. R. Soc. Vic. 85, 163-195.

392 [31] Therneau, TM. 2020 coxme: mixed effects cox models. $R$ package v2.2-16. (

393 [32] Hosmer, D, Lemeshow, S \& May, S. 2008 Applied survival analysis: regression modeling of time-

394 to-event data. 2nd edn ed. Hoboken, NJ, Wiley.

395 [33] Barton, K. 2020 MuMin: multi-model inference. $R$ package v1.43.17. (

396 [34] Therneau, TM. 2021 survival: survival analysis. R package v3.2-11. (

397 [35] Kassambara, A, Kosinski, M, Biecek, P \& Fabian, S. 2021 survminer: drawing survival curves using 398 'ggplot2'. $R$ package v0.4.9. (

399 [36] Jones, E \& Coman, B. 1981 Ecology of the feral cat, Felis catus (L.), in South-Eastern Australia I.

400 Diet. Wildl. Res 8, 537. (doi:10.1071/wr9810537).

401 [37] Paltridge, R, Gibson, D \& Edwards, G. 1997 Diet of the Feral Cat (Felis catus) in Central Australia.

402 Wildl. Res 24, 67. (doi:10.1071/wr96023).

403 [38] Huijbers, CM, Schlacher, TA, Schoeman, DS, Olds, AD, Weston, MA \& Connolly, RM. 2015

404 Limited functional redundancy in vertebrate scavenger guilds fails to compensate for the loss of

405 raptors from urbanized sandy beaches. Divers. Distrib. 21, 55-63. (doi:10.1111/ddi.12282).

406 [39] Hill, JE, Devault, TL, Beasley, JC, Rhodes, OE \& Belant, JL. 2018 Effects of vulture exclusion on

407 carrion consumption by facultative scavengers. Ecol. Evol. 8, 2518-2526. (doi:10.1002/ece3.3840). 
408 [40] Fielding, MW, Buettel, JC, Brook, BW, Stojanovic, D \& Yates, LA. 2021 Roadkill islands: carnivore

409 extinction shifts seasonal use of roadside carrion by generalist avian scavenger. J. Anim. Ecol.

410 (doi:10.1111/1365-2656.13532).

411 [41] Spencer, EE, Dickman, CR, Greenville, A, Crowther, MS, Kutt, A \& Newsome, TM. 2021 Carcasses 412 attract invasive species and increase artificial nest predation in a desert environment. Glob. Ecol.

413 Biogeogr., e01588. (doi:10.1016/j.gecco.2021.e01588).

414 [42] Fancourt, BA. 2016 Avoiding the subject: the implications of avoidance behaviour for detecting 415 predators. Behav. Ecol. Sociobiol. 70, 1535-1546. (doi:10.1007/s00265-016-2162-7).

416 [43] Lazenby, BT \& Dickman, CR. 2013 Patterns of detection and capture are associated with 417 cohabiting predators and prey. PLOS ONE 8, e59846. (doi:10.1371/journal.pone.0059846).

418 [44] Linnell, JDC \& Strand, O. 2000 Interference interactions, co-existence and conservation of 419 mammalian carnivores. Divers. Distrib. 6, 169-176. (doi:10.1046/j.1472-4642.2000.00069.x).

420 [45] Andersen, GE, Johnson, CN, Barmuta, LA \& Jones, ME. 2017 Dietary partitioning of Australia's 421 two marsupial hypercarnivores, the Tasmanian devil and the spotted-tailed quoll, across their shared 422 distributional range. PLOS ONE 12, e0188529. (doi:10.1371/journal.pone.0188529).

423 [46] Jones, ME \& Barmuta, LA. 2000 Niche differentiation among sympatric Australian dasyurid 424 carnivores. J. Mammal. 81, 434-447. (doi:10.1644/1545-1542(2000)081<0434:ndasad>2.0.co;2).

425 [47] Morales-Reyes, Z, Sánchez-Zapata, JA, Sebastián-González, E, Botella, F, Carrete, M \& Moleón, 426 M. 2017 Scavenging efficiency and red fox abundance in Mediterranean mountains with and without 427 vultures. Acta Oecol 79, 81-88. (doi:10.1016/j.actao.2016.12.012).

428 [48] Markandya, A, Taylor, T, Longo, A, Murty, MN, Murty, S \& Dhavala, K. 2008 Counting the cost of 429 vulture decline-An appraisal of the human health and other benefits of vultures in India. Ecol. Econ 430 67, 194-204. (doi:10.1016/j.ecolecon.2008.04.020).

431 [49] Donaghey, R. 2003 The fauna of King Island: a guide to identification and conservation 432 management. (King Island Natural Resource Management Group Inc.

433 [50] Madden, CF, Arroyo, B \& Amar, A. 2015 A review of the impacts of corvids on bird productivity 434 and abundance. Ibis 157, 1-16. (doi:10.1111/ibi.12223). 
435 [51] Webb, MH, Holdsworth, M, Stojanovic, D, Terauds, A, Bell, P \& Heinsohn, R. 2016 Immediate

436 action required to prevent another Australian avian extinction: the King Island Scrubtit. Emu 116,

437 223-229. (doi:10.1071/MU15099).

438 [52] Fielding, MW, Buettel, JC, Nguyen, H \& Brook, BW. 2020 Ravens exploit wildlife roadkill and

439 agricultural landscapes but do not affect songbird assemblages. Emu 120, 11-21.

440 (doi:10.1080/01584197.2019.1629820).

441 [53] Woinarski, JCZ, Murphy, BP, Legge, SM, Garnett, ST, Lawes, MJ, Comer, S, Dickman, CR, Doherty,

442 TS, Edwards, G, Nankivell, A, et al. 2017 How many birds are killed by cats in Australia? Biol. Conserv.

$443 \quad 214,76-87$. (doi:10.1016/j.biocon.2017.08.006).

444 [54] Dickman, CR. 1996 Overview of the impacts of feral cats on Australian native fauna. Canberra,

445 Australian Nature Conservation Agency.

446 [55] Ogada, DL, Torchin, ME, Kinnaird, MF \& Ezenwa, VO. 2012 Effects of vulture declines on

447 facultative scavengers and potential implications for mammalian disease transmission. Conserv. Biol.

$448 \quad 26,453-460$. (doi:10.1111/j.1523-1739.2012.01827.x).

449 [56] Sweeney, OF, Turnbull, J, Jones, M, Letnic, M, Newsome, TM \& Sharp, A. 2019 An Australian

450 perspective on rewilding. Conserv. Biol. 33, 812-820. (doi:10.1111/cobi.13280).

451 [57] Fielding, MW, Buettel, JC \& Brook, BW. 2020 Trophic rewilding of native extirpated predators on 452 Bass Strait Islands could benefit woodland birds. Emu 120, 260-262.

453 (doi:10.1080/01584197.2020.1797509).

454 [58] Derham, TT, Duncan, RP, Johnson, CN \& Jones, ME. 2018 Hope and caution: rewilding to

455 mitigate the impacts of biological invasions. Philos. Trans. R. Soc. B 373, 20180127.

456 (doi:10.1098/rstb.2018.0127).

457 
bioRxiv preprint doi: https://doi.org/10.1101/2021.09.06.459188; this version posted September 6, 2021. The copyright holder for this preprint (which was not certified by peer review) is the author/funder, who has granted bioRxiv a license to display the preprint in perpetuity. It is made available under aCC-BY-NC-ND 4.0 International license.

459 Table 1. Total foraging times and proportion of total foraging time for the top four scavengers in

460 each scavenger community.

\begin{tabular}{llcc}
\hline $\begin{array}{l}\text { Scavenger } \\
\text { community }\end{array}$ & Species & $\begin{array}{c}\text { Time foraging } \\
\text { (hours) }\end{array}$ & $\begin{array}{c}\text { Proportion total foraging } \\
\text { time (overall) }\end{array}$ \\
\hline Full & Tasmanian devil (Sarcophilus harrisii) & 108.6 & $70.7 \%$ \\
& Forest raven (Corvus tasmanicus) & 26.5 & $17.3 \%$ \\
& Spotted-tailed quoll (Dasyurus maculatus) & 8.3 & $5.4 \%$ \\
& Feral cat (Felis catus) & 4.8 & $3.1 \%$ \\
\hline Reduced & Forest raven (Corvus tasmanicus) & 238.7 & $47.9 \%$ \\
& Spotted-tailed quoll (Dasyurus maculatus) & 118.9 & $23.9 \%$ \\
& Tasmanian devil (Sarcophilus harrisii) & 81.2 & $16.3 \%$ \\
\hline Simple & Feral cat (Felis catus) & 23.3 & $4.6 \%$ \\
& Forest raven (Corvus tasmanicus) & 448.3 & $88.2 \%$ \\
& Feral cat (Felis catus) & 33.9 & $7.0 \%$ \\
& Black rat (Rattus rattus) & 8.7 & $1.7 \%$ \\
& Black currawong (Strepera fuliginosa) & 5.3 & $1.0 \%$ \\
\hline
\end{tabular}

461 


\section{$462 \quad$ Figure Legends}

463 Figure 1. Geographic location of study sites across Northern Tasmania and the Bass Strait Islands.

464 Each shape indicates a site that contains between 6 to 8 camera traps.

465 Figure 2. The proportion of carcasses persisting in the environment for each level of scavenger

466 diversity and abundance. Colour dashed lines indicate the $95 \%$ confidence interval. Black dotted line

467 shows the median carcass persistence times for each of the three categories.

468 Figure 3. The proportion of carcasses not discovered by (a) all species, (b) forest ravens and (c) feral

469 cats for each level of scavenger diversity and abundance. Colour dashed lines indicate the 95\%

470 confidence interval.

471 Figure 4. Carcass consumption by forest ravens. Top row: (a) the proportion of total carcasses

472 foraged, with the response curves of the best predictors, being (b) devil scavenging time and (c) devil

473 activity. Bottom row: (d) the average proportion of total foraging time with the response curve of

474 the best predictor, (e) devil scavenging time. In (a) and (d) each dot corresponds to the mean value

475 for the study sites and error bars are bootstrapped 95\% confidence intervals.

476 Figure 5. Carcass consumption by feral cats: (a) the proportion of total carcasses foraged, and (b) the

477 response curves of the best predictor, devil activity. In (a) each dot corresponds to the mean value

478 for the study sites and error bars are bootstrapped $95 \%$ confidence intervals. 


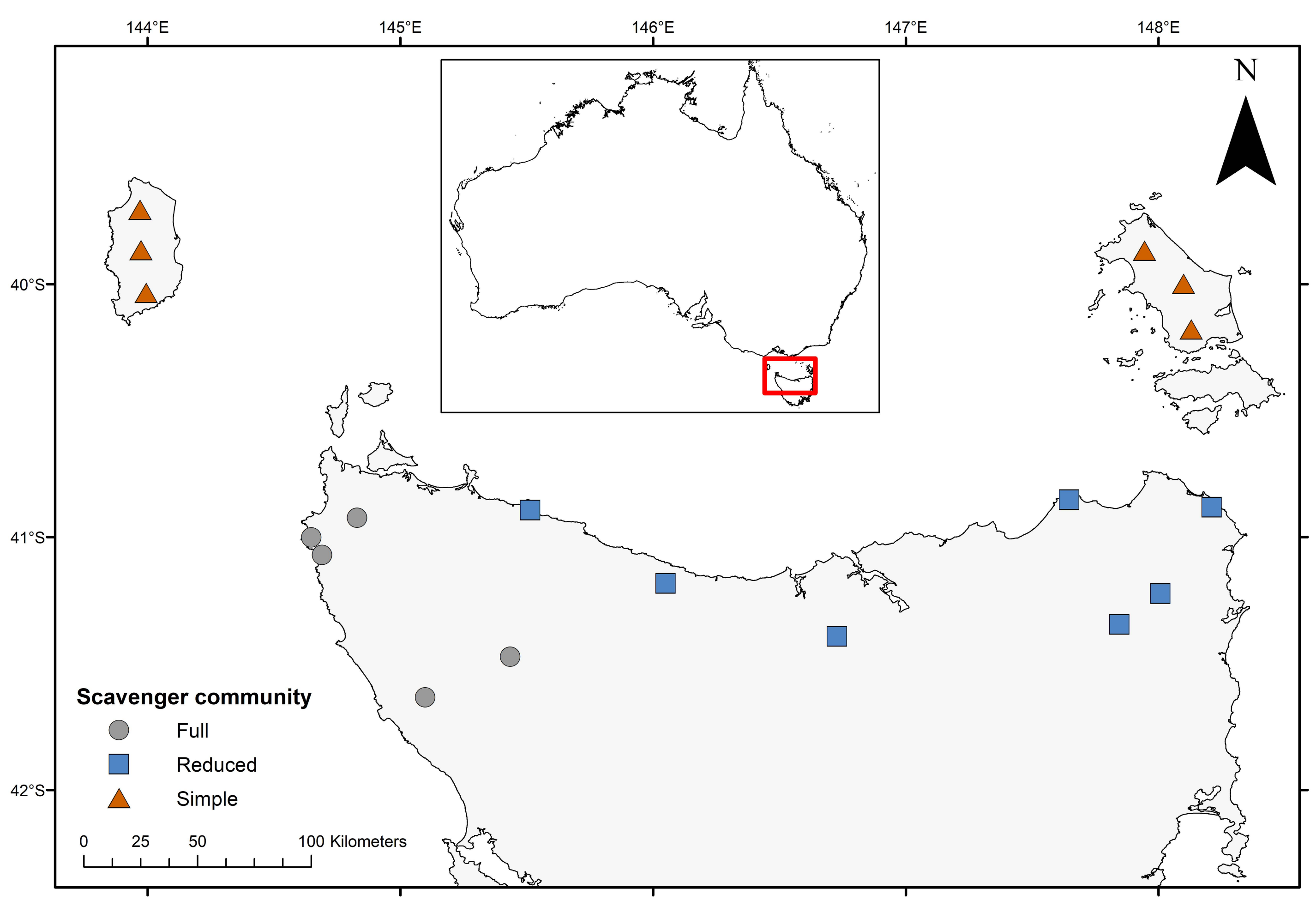




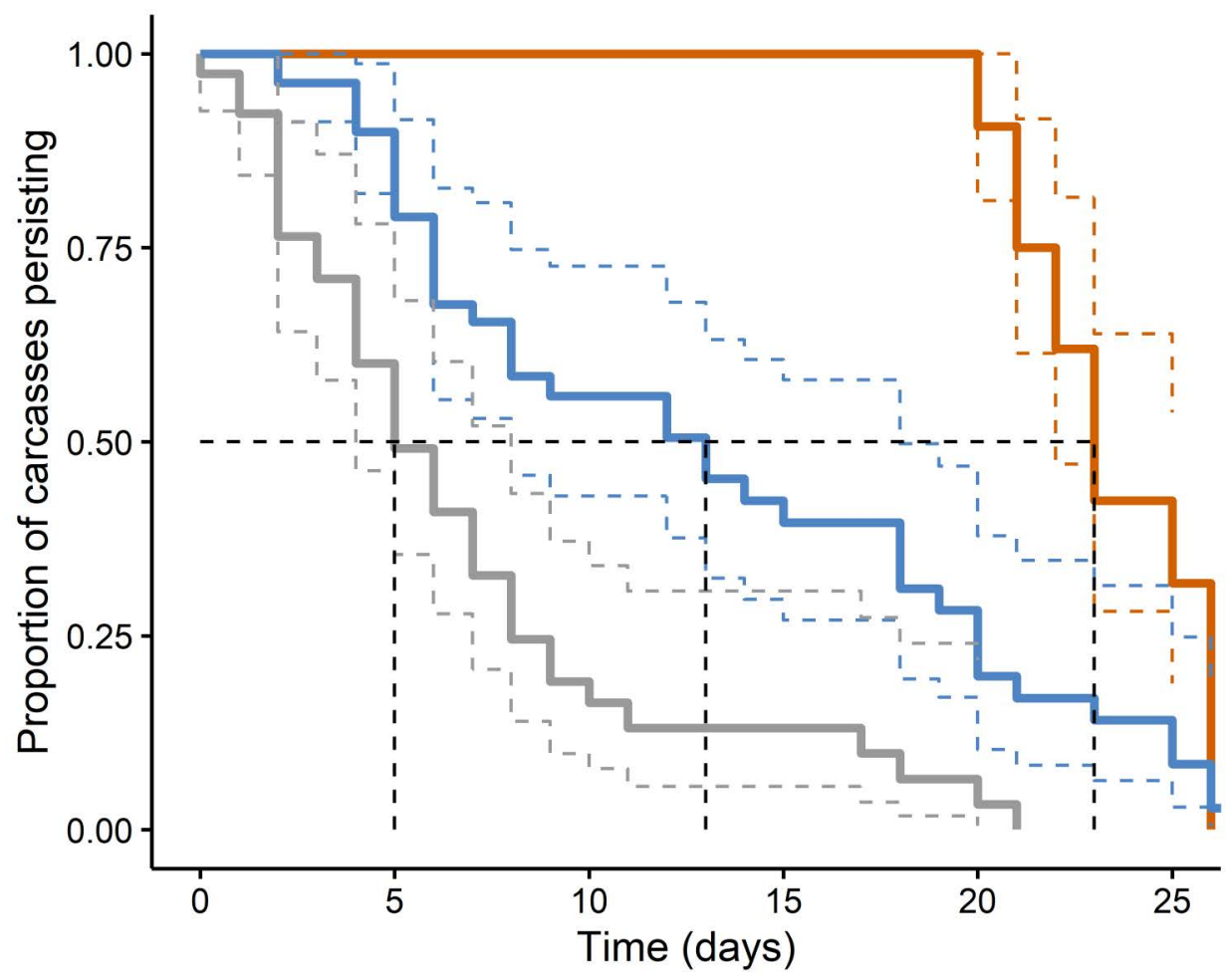

Scavenger community:

Simple

Reduced

Full 

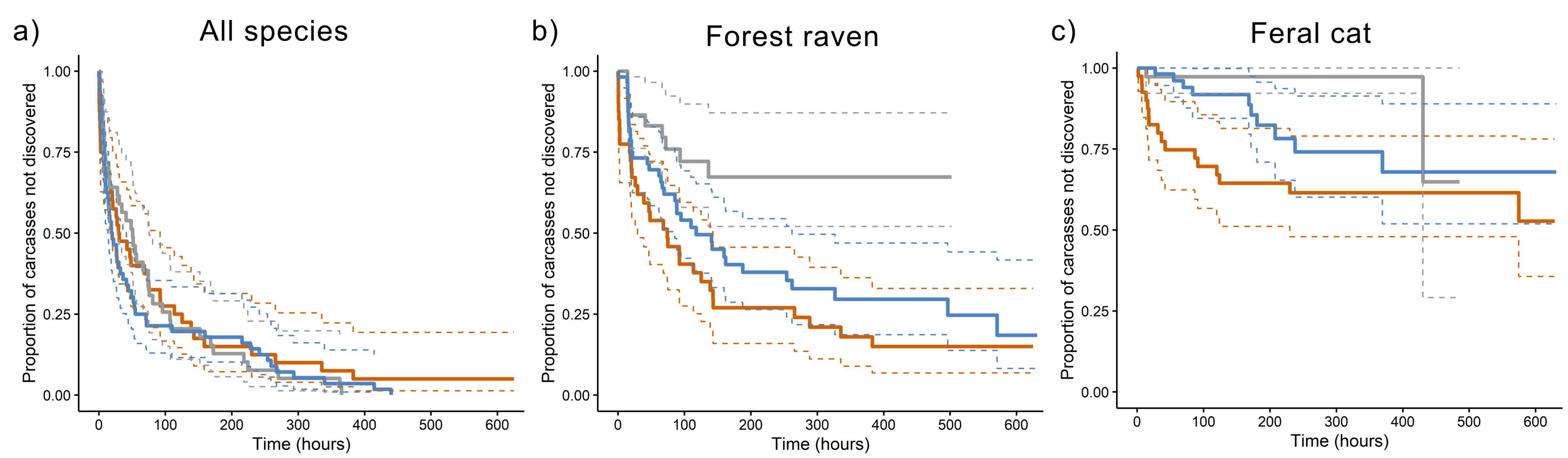

Scavenger community: - Simple - Reduced - Full 


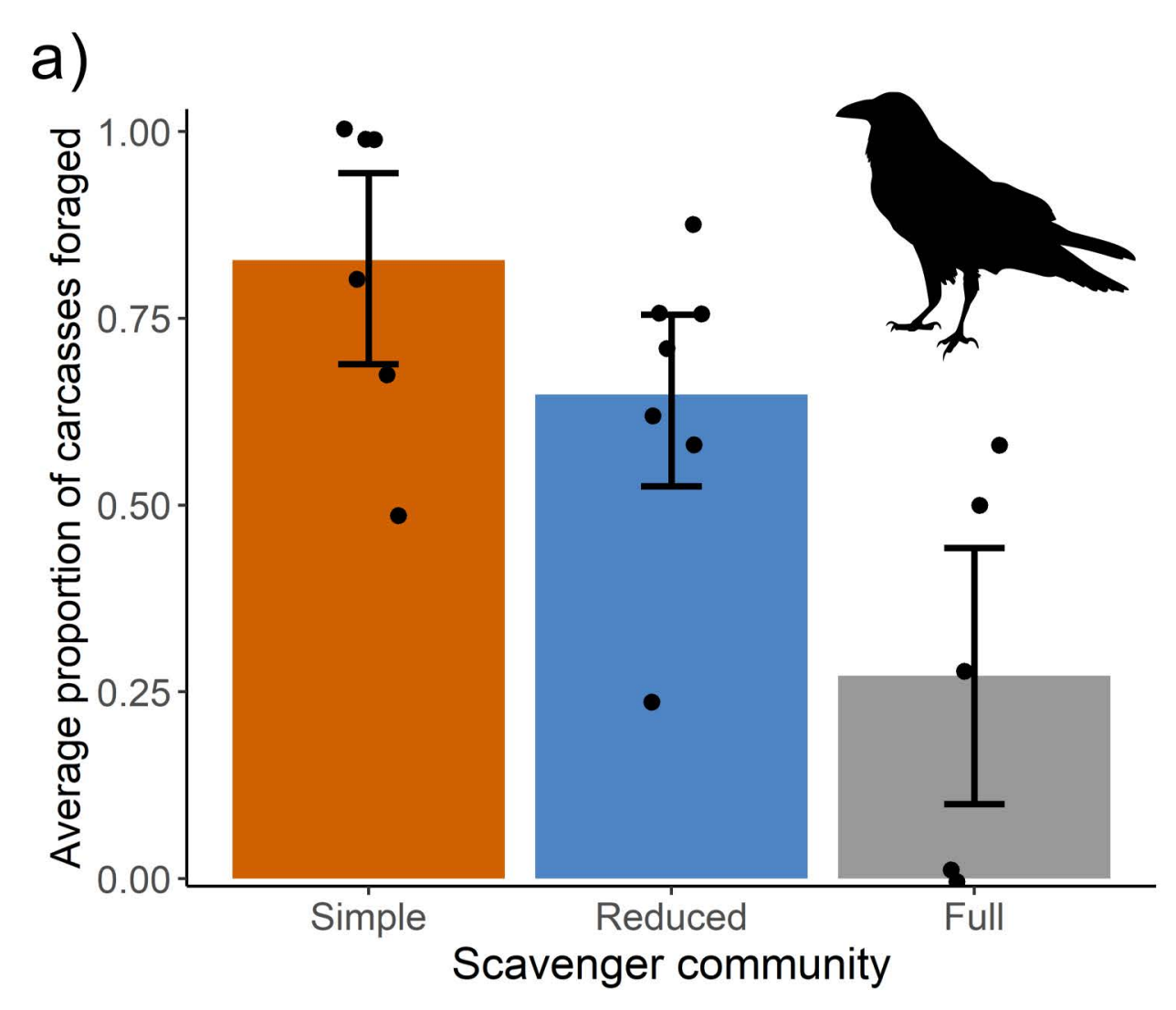

b)

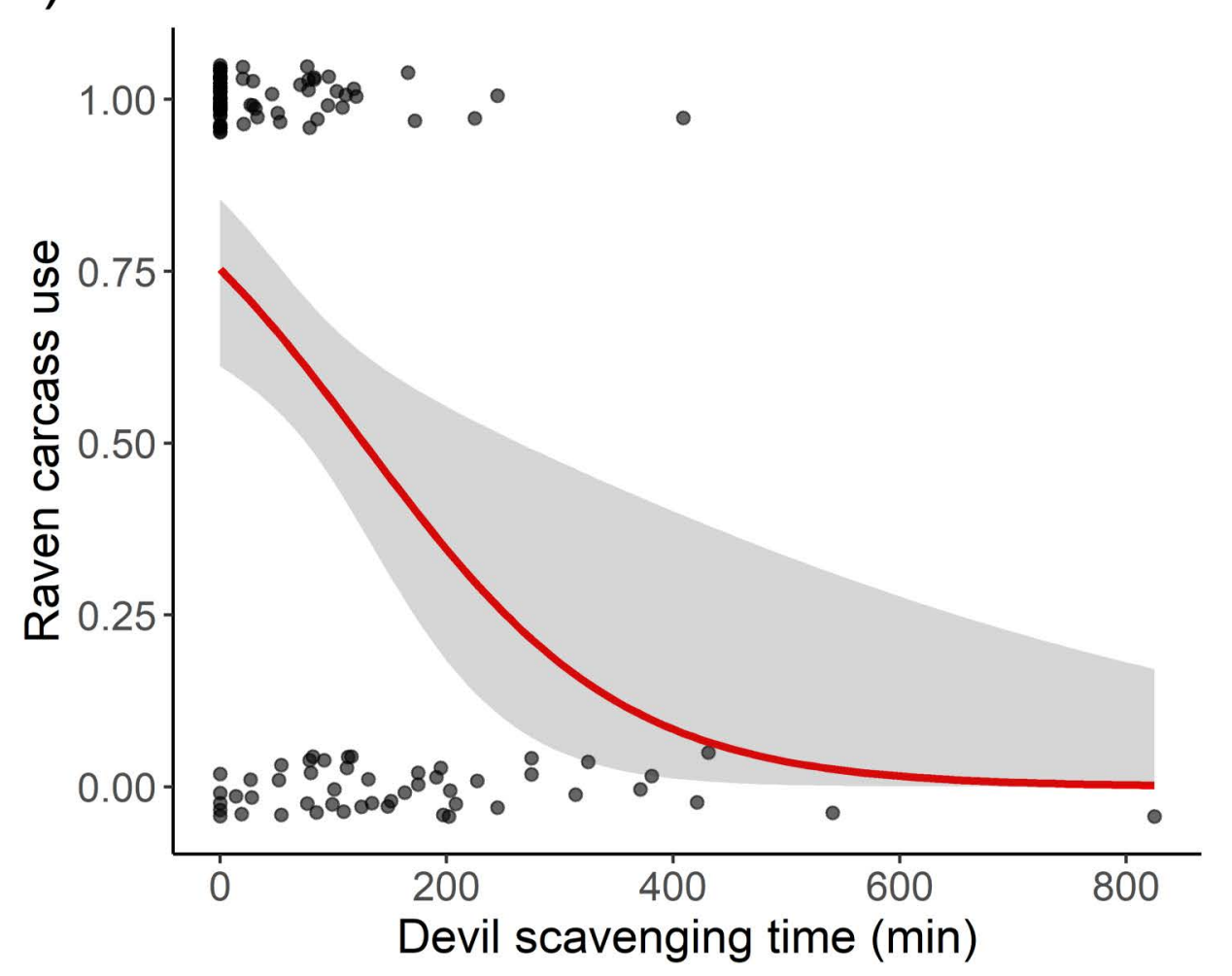

c)

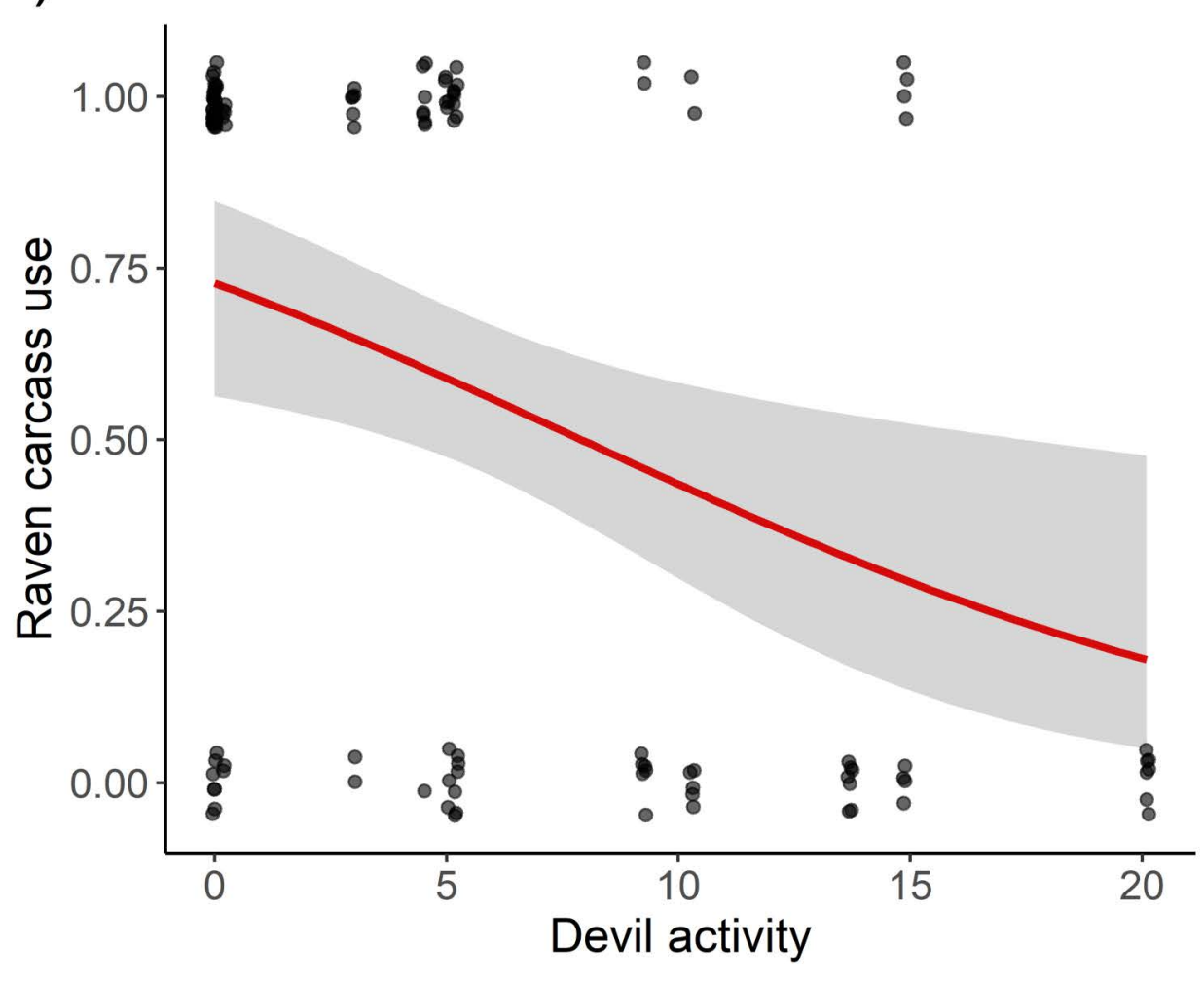

d)

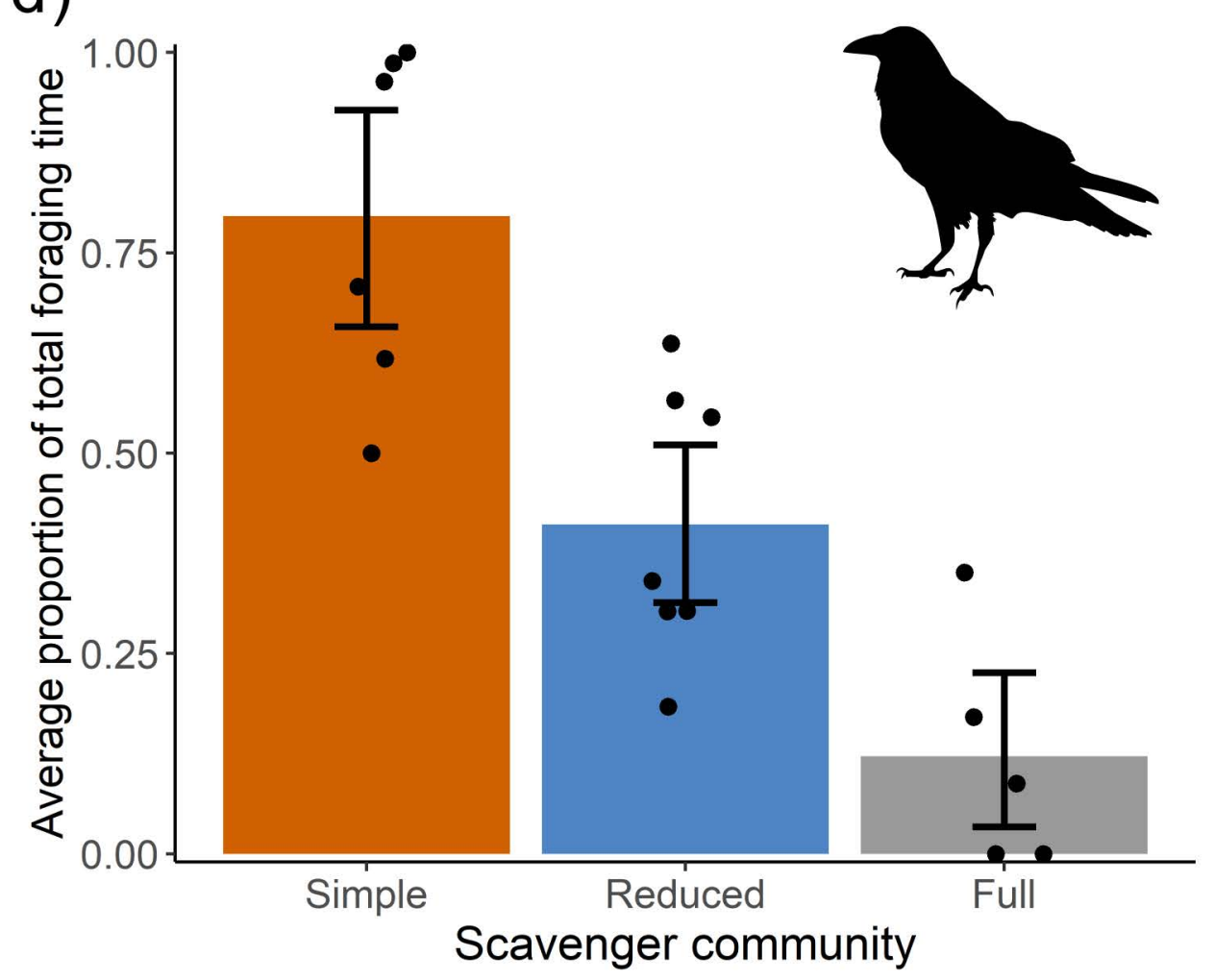

e)

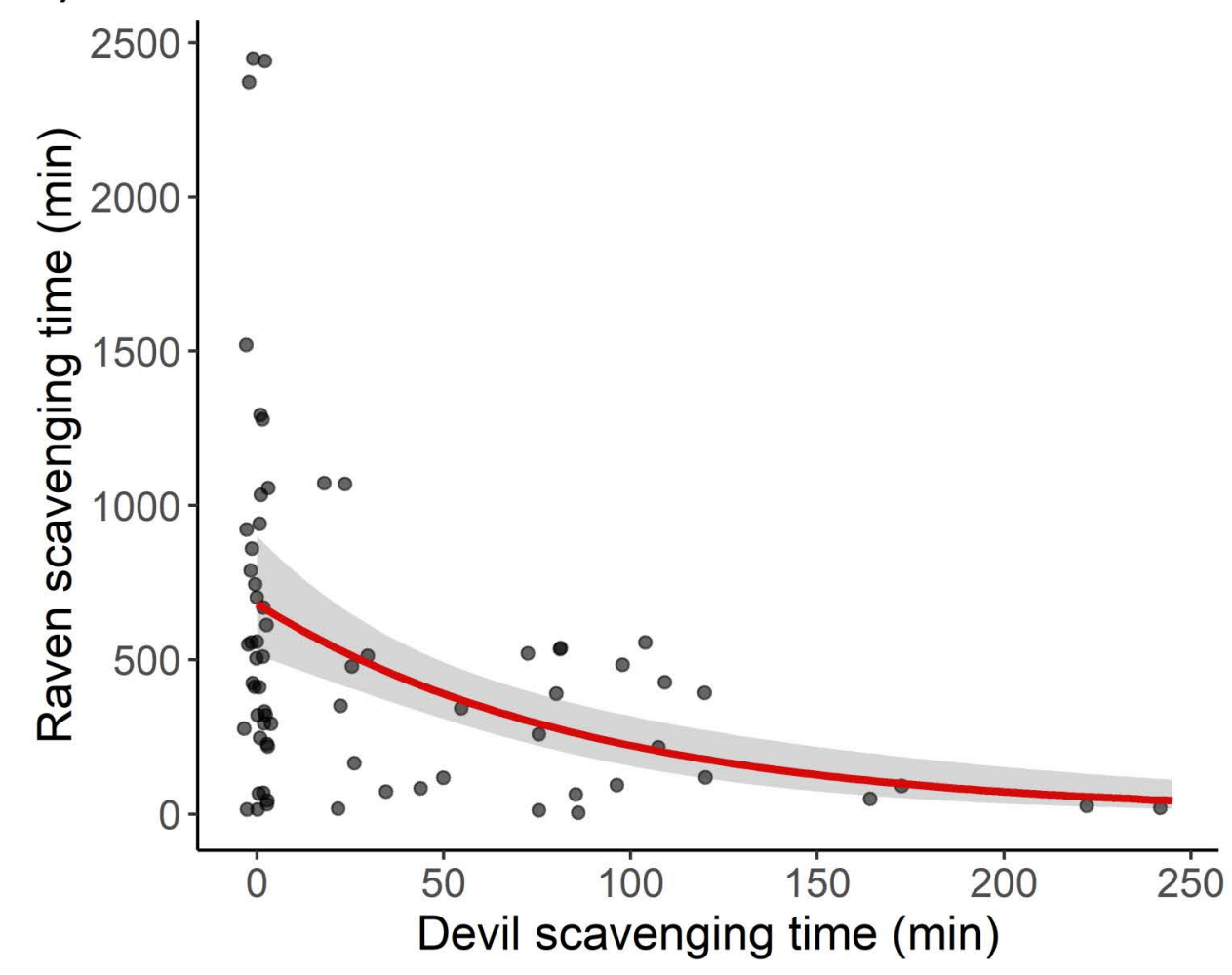


a)

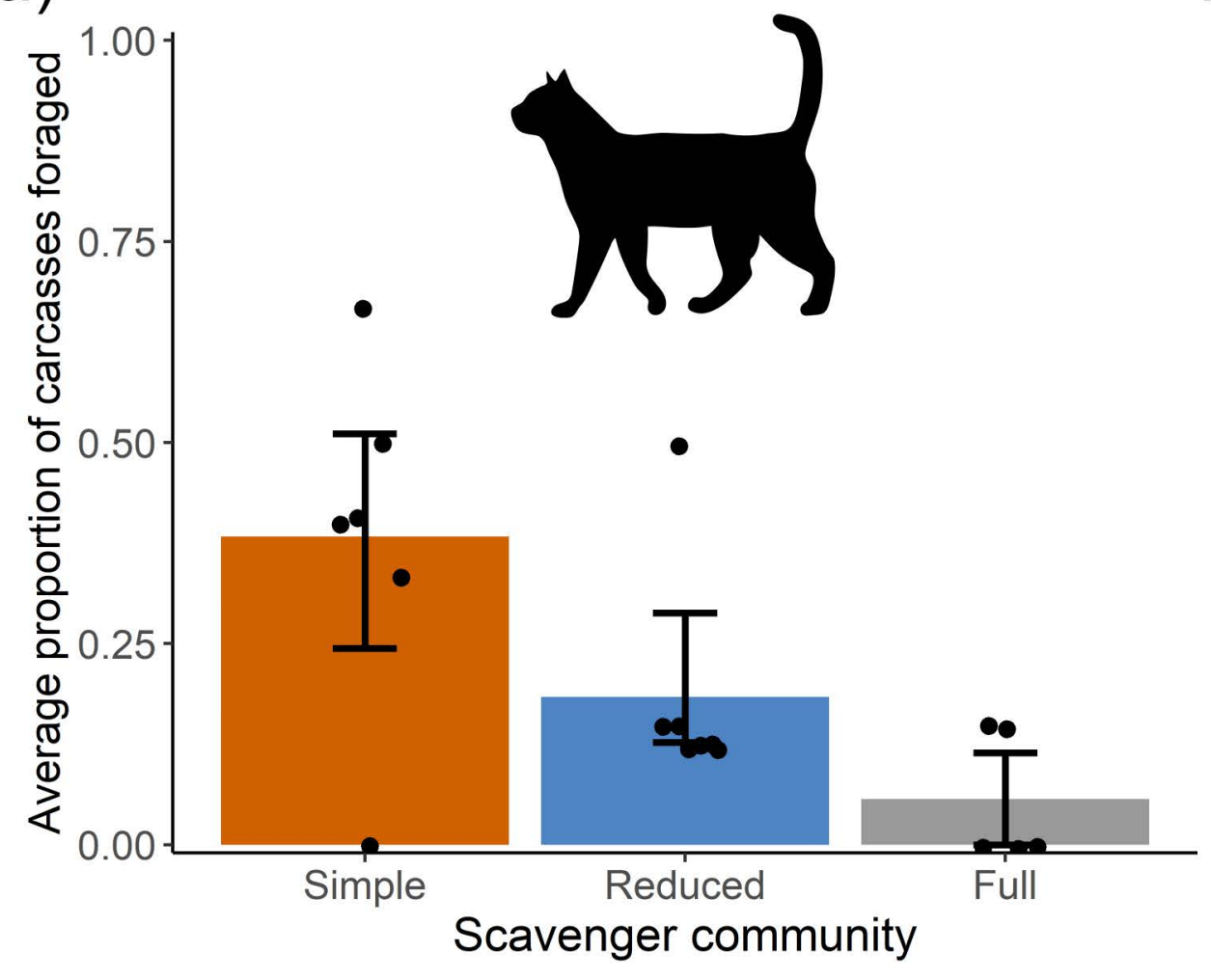

b)

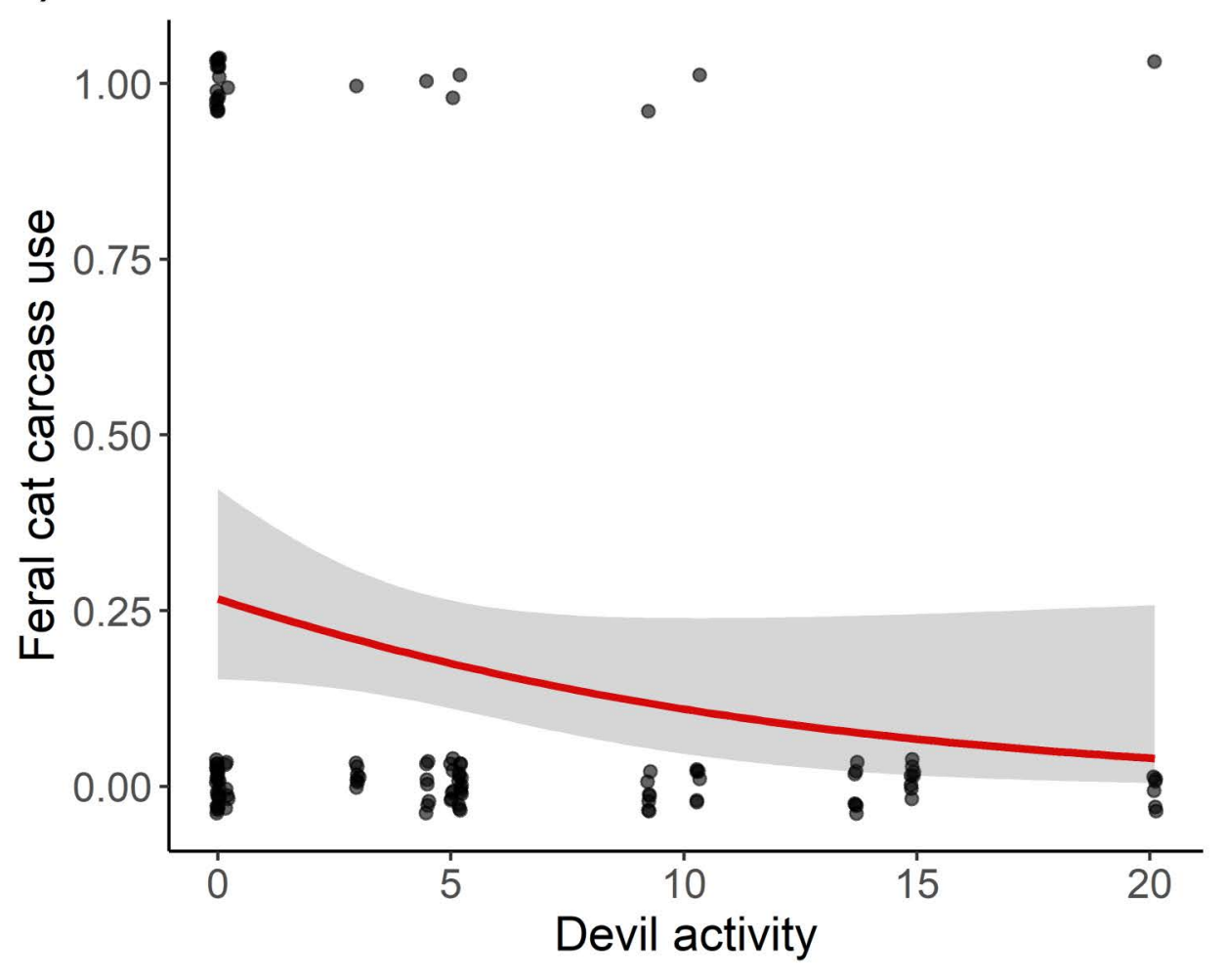

